\title{
AUTOMATIZACIJA POSTROJENJA ZA SKLADIŠTENJE I PRETAKANJE METANOLA U POGONU ZA PROIZVODNJU BIODIZELA
}

\author{
AUTOMATION OF SECTION FOR STORAGING AND TRANSFUSION \\ OF METHANOL IN BIODIESEL PRODUCTION PLANT
}

\author{
Stanko P. STANKOV ${ }^{1)}$, Saša P. ARSIĆ(2), Zoran D. ICIĆ ${ }^{1)}$, Nikola B. DANKOVIĆ( \\ ${ }^{1)}$ Elektronski fakultet Univerziteta u Nišu, Niš; \\ ${ }^{2)}$ EPS Elektrodistribucija, Prokuplje
}

\begin{abstract}
Opisan je sistem za akviziciju podataka, nadzor i upravljanje postrojenjem za skladištenje i pretakanje metil alkohola, koji se koristi kao reaktant u tehnološkom procesu (proizvodnja biodizela u sklopu Fabrike FAM Kruševac). Upravljanje i nadzor se vrše pomoću PLC i SCADA sistema. Pregled $i$ zadavanje karakterističnih parametara $i$ veličina vrši se preko kreiranih ekrana na touch panelu $i P C$ računaru na kome se izvršava arhiviranje podataka. Pod nadzorom SCADA su: diskretni i kontinualni nivoi rezervoara za skladištenje metanola, statusi pumpi za pretakanje, temperature metanola $u$ rezervoarima i cevovodu, pritisak u cevovodu i maseni protok metanola. Omogućeno je arhiviranje podataka i generisanje izveštaja.
\end{abstract}

Ključne reči: metanol; skladište; pretakanje upravljanje; nadzor

This paper describes a system for data acquisition, monitoring and control of plant for the storage and transfusion of methyl alcohol, which is used as a reactant in the technological process (production of biodiesel in the factory FAM Kruševac). Control and monitoring are performed by a PLC and SCADA system. Viewing and setting the characteristic parameters and variables is done through the created screen on the touch panel and PC computer that executes data archiving. Under the supervision of SCADA are: discrete and continuous levels in tanks for storing methanol, status of pumps for transfusion, the temperature of methanol in tanks and pipeline, the pressure in the pipeline and the mass flow rate of methanol.

Key words: methanol; storage; transfusion; control; supervision

\section{Uvod}

Metil estar biljnih ulja (MEBU) čiji je komercijalni naziv biodizel dobija se u složenom procesu transesterifikacije triglicerida masnih kiselina u metilestre masnih kiselina. Ovi trigliceridi su sastavni elementi sirovih biljnih ulja i otpadnih jestivih ulja. Pre ovog procesa vrši se rafinacija sirovog ulja (faza neutralizacije i faza hidratacije). Za ubrzanje hemijske reakcije transesterifikacije potrebno je dodavati katalizator. Najčešće se u ulozi katalizatora koriste natrijum hidroksid $(\mathrm{NaOH})$ ili kalijum hidroksid (KOH) kojima se dodaje bezvodni metanol (metil alkohol) - $\mathrm{CH}_{3} \mathrm{OH}$, pri čemu se rastvaranjem alkalnih hidroksida obrazuje natrijum metilat $\left(\mathrm{NaOCH}_{3}\right)$, odnosno kalijum metilat $\left(\mathrm{KOCH}_{3}\right)$. Priprema katalizatora se obavlja u reaktoru i budući da je hemijski proces pripreme rastvora katalizatora egzoterman, potrebno je ovaj rastvor kontinualno hladiti uz neprekidno mešanje. Na slici 1 je prikazana uprošćena blok šema proizvodnje biodizela na kojoj se vidi uloga metanola. Pripremljeni katalizator se iz reaktora zatvorenim sistemom odvodi do rezervoara za skladištenje. Nakon transesterifikacije slede postupci demetanolizacije, ekstrakcije sapuna, filtriranja, aditiviranja, sušenja i skladištenja biodizela. U toku pripreme katalizatora koristi se i tzv. povratni metanol koji nastaje u procesu dematanolizacije MEBU. On se prečišćava, meša s novim bezvodnim metanolom i vraća u proces, što doprinosi ostvarivanju ekološke i ekonomične proizvodnje [1 - 4]. Za godišnju proizvodnju 20.000 t biodizela potrebno je $2.400 \mathrm{t}$ metanola. Koncentracija metanola u sirovom biodizelu je posledica neizreagovanog viška reaktanata u procesima koji se odvijaju u I - oj i II - oj fazi transesterifikacije [4]. 


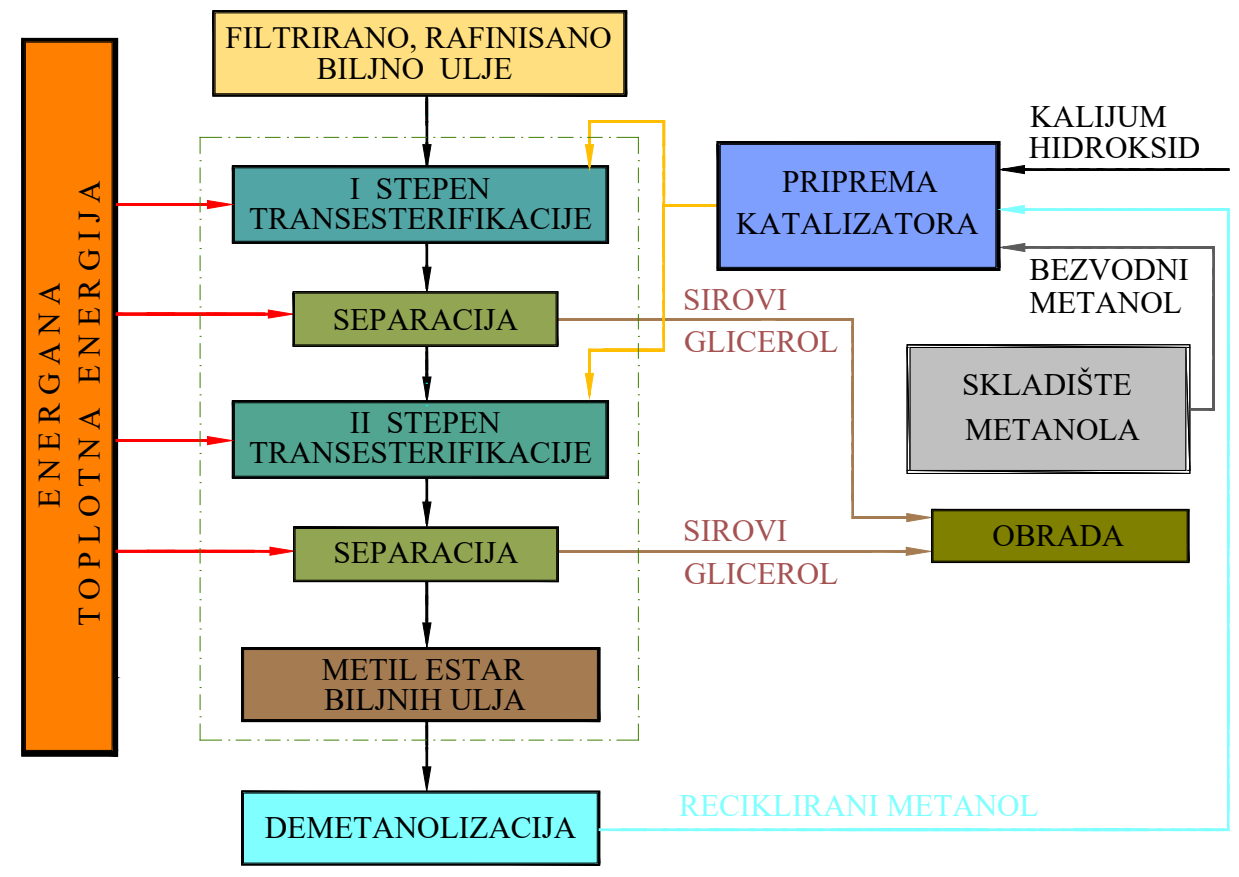

Slika 1. Uprošćena blok šema proizvodnje biodizela iz biljnog ulja

\section{Upravljanje i nadzor skladištenje i pretakanja metanola}

Skladištenje metanola, koji se doprema autocisternama obavlja se u rezervoarima R1, R2, R3 i R4 koji imaju duple zidove. SCADA ekran skladišta metanola je prikazan na slici 2.

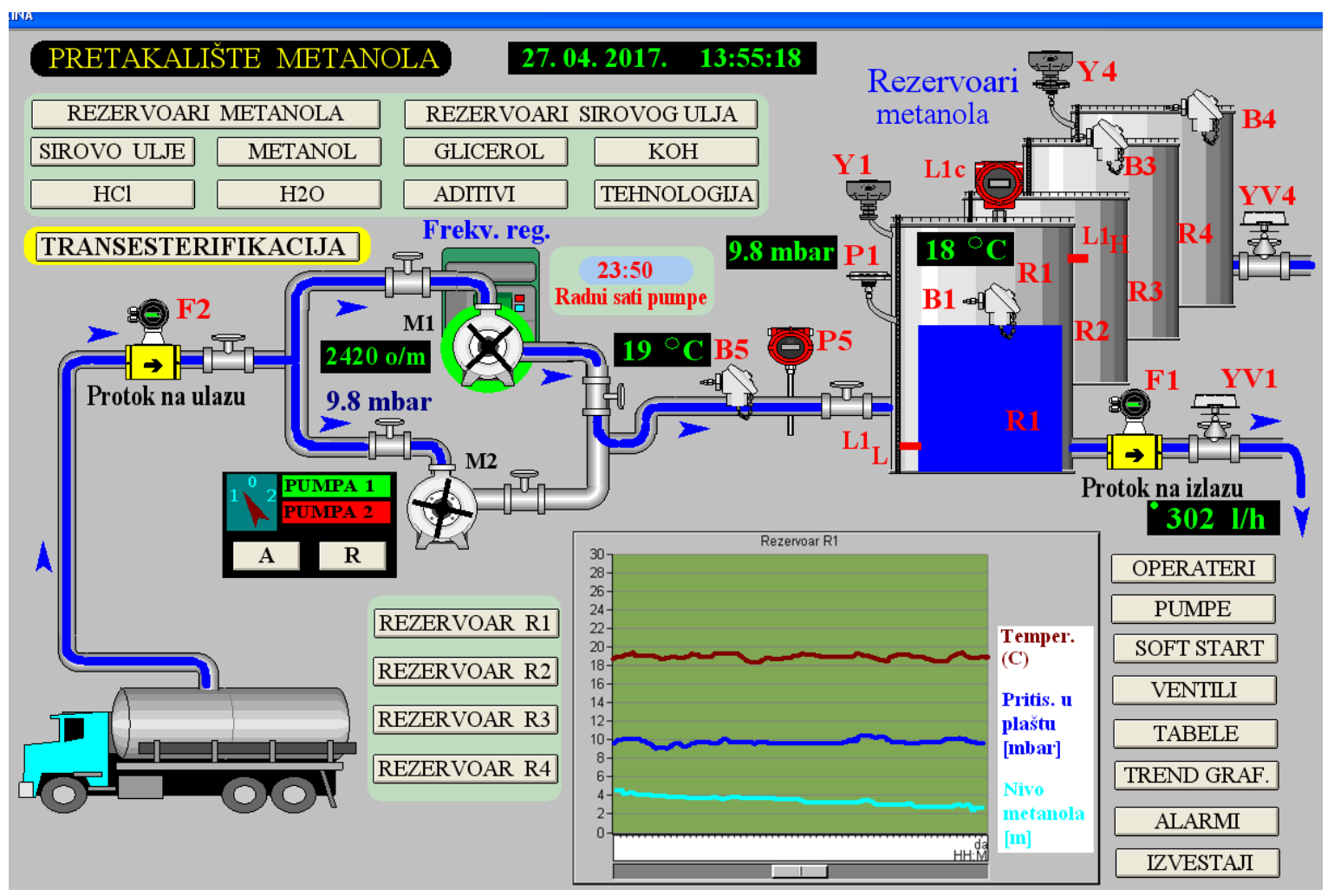

Slika 2. Jedan SCADA ekran skladištenja i pretakanja metanola

Pretakanje iz cisterne u rezervoare vrši se pomoću centrtifugalnih pumpi M1, M2 (radna, čija je pozadina označena zelenom bojom i rezervna). Kapacitet pumpe $\left(20-40 \mathrm{~m}^{3} / \mathrm{h}\right)$ je određen brzinom 
motora koja se reguliše pomoću frekventnog regulatora. Cevovodi DN 80 omogućavaju da se pri kapacitetu pumpe $20 \mathrm{~m}^{3} / \mathrm{h}$ postiže brzina strujanja metanola $1.1 \mathrm{~m} / \mathrm{s}$, a kod kapacitetu $40 \mathrm{~m}^{3} / \mathrm{h}$ strujanje se odvija brzinom $2.2 \mathrm{~m} / \mathrm{s}$. Na slici 3 prikazan je trend graf brzine proticanja metanola (frekvencija elektromotora je $64 \mathrm{~Hz}$ ) [4].

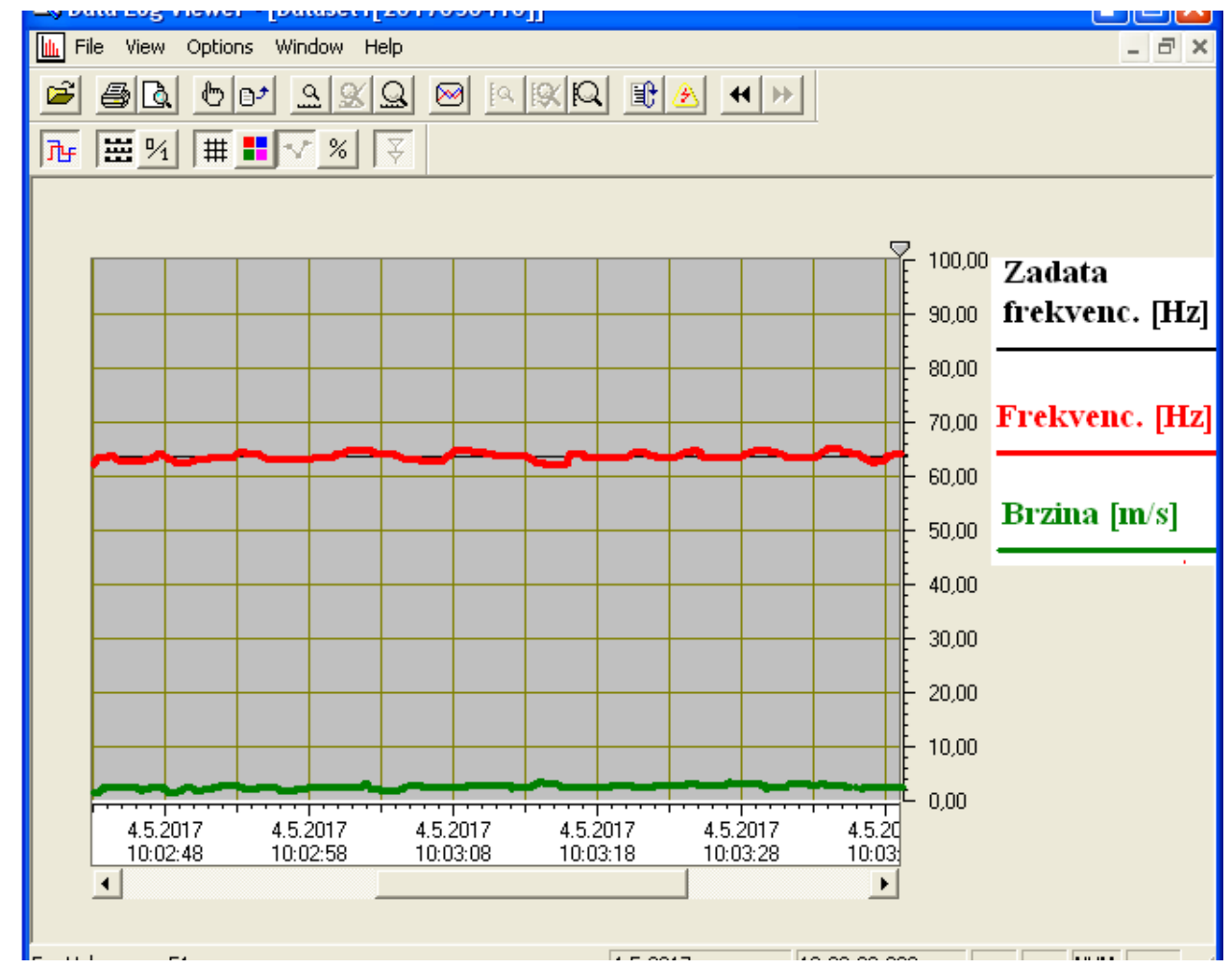

Slika 3. Trend graf brzine proticanja metanola

Uloge pumpi, koje mogu raditi u ručnom ili automatskom režimu, se menjaju prema definisanom vremenu. Rezervoari su međusobno povezani preko cevovoda i elektropneumatskih ventila, što omogućava da se preusmeravanje metanola iz rezervoara u rezervoar vrši korišćenjem postojećih pumpi i otvaranjem odgovarajućih grana pomoću pomenutih ventila. Potreba za ovim se javlja prilikom servisiranja i održavanja rezervoara i opreme. Ventili se pokreću komprimovanim azotom (inertan gas koji ne mrzne do $-40{ }^{\circ} \mathrm{C}$ ). Kod istakanju iz cisterne vrši se merenje protoka metanola pomoću masenog merača protoka (oznaka F2 na slici 2) koji poseduje lokalni displej, pri čemu se kontinualno nadgledaju i memorišu: maseni protok, trenutna gustina i temperatura metanola. Isti merač protoka (F1) je instaliran i na zajedničkom izlazu rezervoara metanola a njime se meri potrošnja metanola $u$ procesu proizvodnje biodizela.

U interesu ekonomične proizvodnje biodizela je da se omogući prečišćavanje viška metanola koji nastaje u tehnološkom procesu i da se on ponovo vrati u proizvodnju. Ovo se ne rešava jednostavno budući da se kod uparavanja biodizela nekom od tehnoloških postupaka, osim prisustva vode postojevi niže masne kiseline koje čine metanol mutnim. Za ovj proces postoji posebna stanica za predestilaciju i regeneraciju metanola.

Metanol se u sirovom biodizelu pretežno pojavljuje kao neizreagovani višak reaktanata u reakcijama koje se odigravaju u I i II fazi transesterifikacije. Njegova prisutnost u finalnom biodizelu nije poželjna jer pogoršava osobine ovog proizvoda kao biogoriva:

- povećava isparljivost biogoriva na niskim temperaturama, čime se snižava temperatura paljenja i poremećuje kriva destilacije, a poremećen je i pravilan rad dizel motora;

- nastaje bubrenje i omekšavanje brtvenih materijala, koji su u kontaktu s biogorivom, skraćuje vek trajanja dizel motora i pumpe visokog pritiska za ubrizgavanje dizel goriva. 
Iz tih razloga svetski standardi koji definišu kvalitet biodizela, ograničavaju prisutnost metanola. Prema normi EN 14214 dozvoljava se maksimalno 0,2 mas\% i tačka paljenja u zatvorenoj posudi od minimalno $120^{\circ} \mathrm{C}$.

Praćenje parametara metanola koji su bitni za nadzor i upravljanje u toku manipulacije i skladištenja, omogućavaju instalirani merni instrumenti:

- radarski merač nivoa tečnosti u svakom rezervoaru (oznaka Lc na SCADA-i),

- granični merači nivoa u rezervoarima $\left(\mathrm{L}_{\mathrm{L}}\right.$ - donji nivo i $\mathrm{L}_{\mathrm{H}}$ - gornji nivo),

- kontinualni merači temperature u rezervoarima - oznaka T1, T2, T3, T4,

- kontinualni merač temperature u cevovodu - T5,

- kontinualni merač pritiska u cevovodu - P5,

- granični merači pritiska gasne faze u duplim plaštovima rezervoara (kontaktni manometri koji ukazuju da je pritisak azota u duplom plaštu ispod predviđene granične vrednosti) - oznaka P1, P2, P3, P4.

Inertizacija gasne faze metanola, koja je potrebna za bezbednost pri sladištenju i manipulaciji i za održavanje stalnog nadpritiska značajna je za smanjenje emisija u atmosferu, što obezbeđuje merno - regulaciona oprema:

- regulator pritiska azota (redukcija pritiska od $600 \mathrm{kPa}$ na $10 \mathrm{mbar}$ i automatsko uvođenje azota u rezervoar pri svakom padu pritiska gasne faze metanola ispod $10 \mathrm{mbar}$ ),

- regulator pritiska gasne faze - "odušni ventili“" na rezervoarima metanola - elektromagnetni ventili Y1, Y2, Y3, Y4 (preko ovih ventila se vrši ispuštanje gasne faze metanola u atmosferu, pri svakom porastu pritiska iznad 15 mbar).

\section{Konfiguracija upravljačko - nadzornog sistema}

Radom pretakališta metanola upravlja lokalni PLC Omron CJ1M s centralnom procesorskom jedinicom CPU21. Kontroler poseduje integrisanih 10 digitalnih ulaza i 6 digitalnih izlaza. Pridodata su dva analogna ulazna modula sa po 8 ulaza i jedan digitalni izlazni modul s 16 izlaza. U sprezi s kontrolerom su touch panel NS Omron i lokalni PC SCADA računar. Frekventni regulator je povezan s kontrolerom preko komunikacije. Upravljački sistem skladišta i pretakališta metanola je smešten u ormaru na čijim vratima je instaliran touch panel (slika 4).

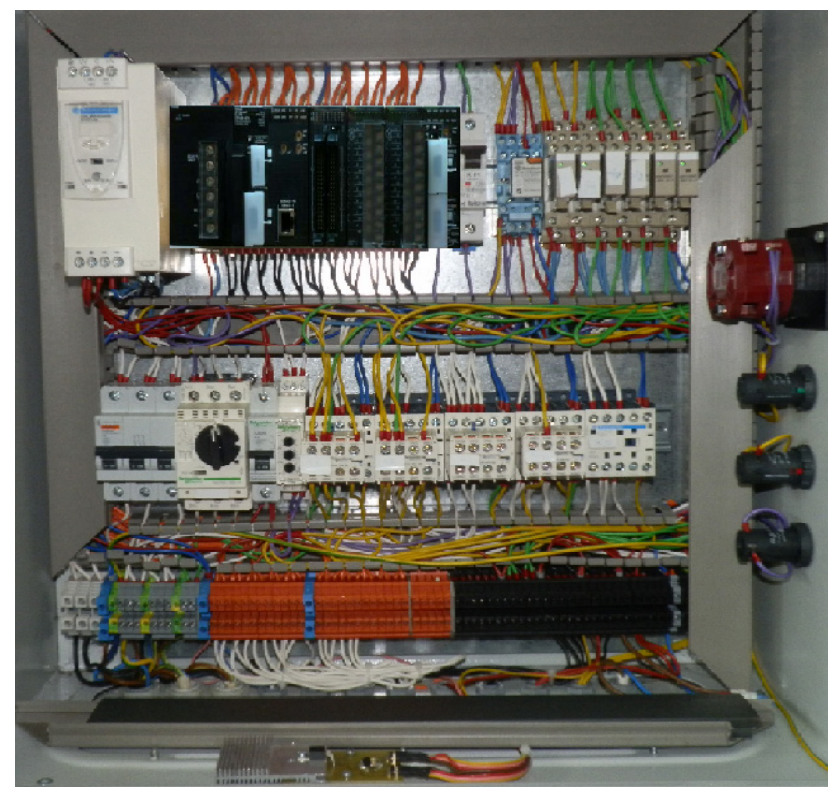

Slika 4. Upravljački ormar pretakališta metanola

Programska platforma je CX - one u kojoj su integrisani: CX - programmer namenjen za programiranje Omron familije kontrolera, CX - supervisor za kreiranje SCADA sistema i CX - designer za programiranje touch panela. Ovaj lokalni PLC je preko Ethernet komunikacije povezan s master PLC konfiguracijom (dva snažna PLC-a Omron CS1G koji čine redundantan sistem) pod čijim su nadzorom i PLC-ovi ostalih tehnoloških celina. Takođe je povezan i s centralnim sistemom nadzora i 
upravljanja (CSNU) [4 - 6]. Veza između procesa i upravljačke logike se ostvaruje preko digitalnih i analognih ulaznih i izlaznih modula. Statusi prekidačkih elemenata (glavni prekidač i osigurači ormara, osigurači motora, termo releji, sigurnosni termostati, merači graničnih nivoa fluida, kontaktni manometri, presostati) vode se na digitalne ulazne module. Signali sa senzori nivoa, pritiska, temperature, protoka, povezani su na ulaze analognih modula. Preko digitalnih i analognih izlaza šalju se komande izvršnim organima (pumpe, elektropneumatski i elektromagnetni ventili). Frekventni regulator je povezan sa upravljačkom jedinicom preko komunikacije. Konfiguracija upravljačko - nadzornog sistema je data na slici 5 [4].

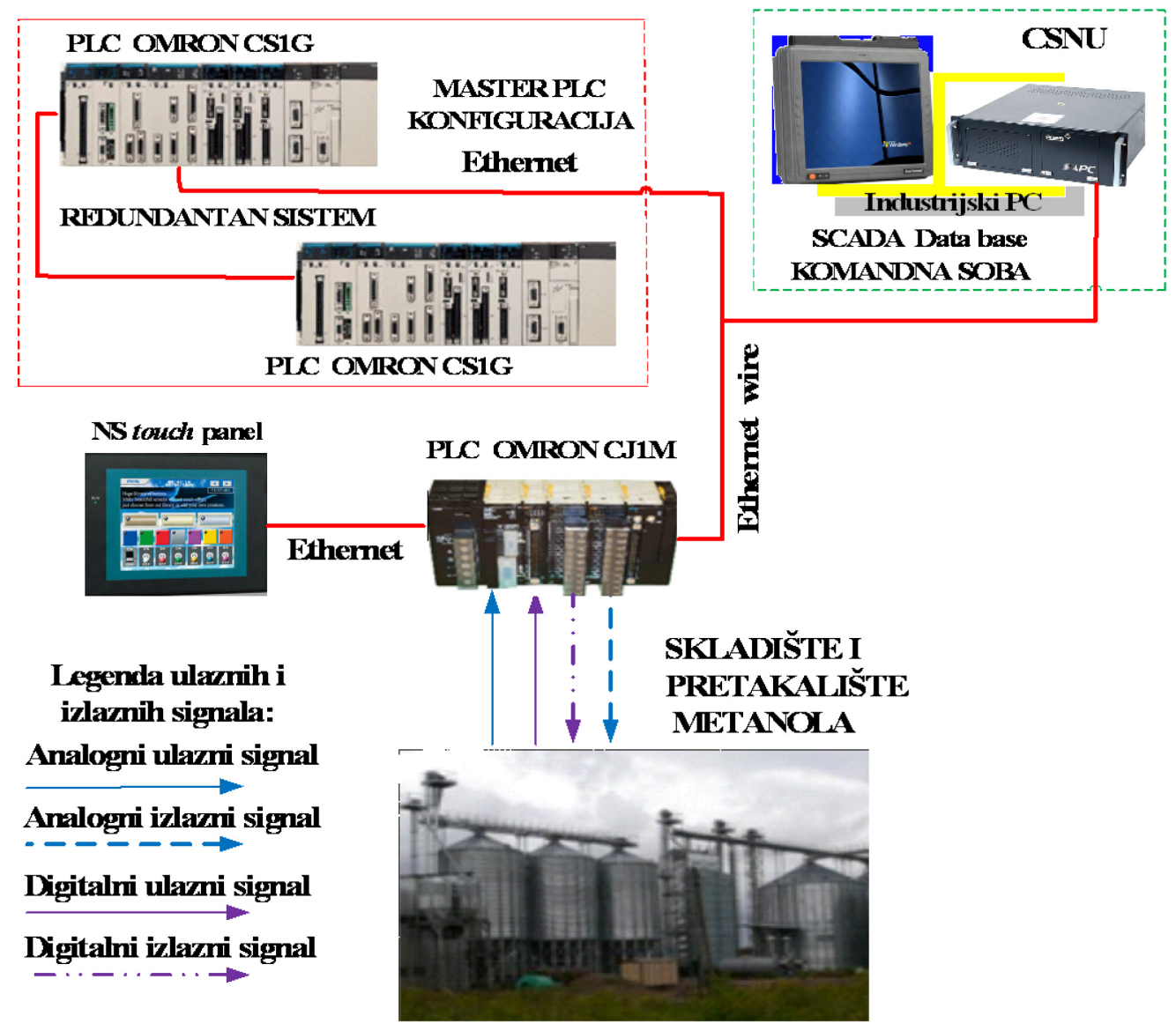

Slika 5. Konfiguracija upravljačko-nadzornog sistema skladišta metanola

\section{Realizacija nadzora}

SCADA služi za akviziciju i arhiviranje podataka, i generisanje izveštaja. Omogućava operateru prikaz informacija o događajima u objektima koji se nadgledaju. Prikaz zavisi od tipa objekta i njegove složenosti. One opcije koje nisu dostupne kod određenog objekta obojene su sivo i njihovo aktiviranje je onemogućeno. Opcije su sortirane počev od onih koje se najčešće koriste ka onima koje se koriste ređe. Kod otvaranja aplikacija iz menija za svaku od odabranih opcija podržan je Windows pristup. Svaka aplikacija se otvara u novom prozoru s mogućnošću umanjenja ili uvećanja, pomeranja na ekranu i spuštanja na liniju. Kombinacijom taster Alt+Tab omogućava se "šetanje" između otvorenih ekrana, kao i povratak na osnovni ekran, što je od koristi kada operater želi da otvori više ekrana i da istovremeno prati događanja u više objekata. Kod SCADA prikaza ptetakališta metanola od interesa je praćenje termičkih, električnih i hidrauličkih parametara.U tom smislu SCADA aplikacija ima tri dela: jedan sa električnim, drugi s hidrauličkim, treći s termičkim parametrima. Oni se uporedo mogu prikazivati na po trećinu ekrana, ili pak pojedinačno. Parametri koji se mere ili preračunavaju prikazuju se na slikama SCADA-e (ali samo oni osnovni koji su dovoljni operateru da ga ne bi opterećivali nepotrebnim podacima). Od parametara koji se prikazuju na električnoj šemi ističu se: parametri motora pumpi (struja-srednja vrednost faznih struja), aktivna snaga (zbir faznih snaga), reaktivna (zbir 
faznih snaga), prividna snaga, $\cos \varphi$, frekvencija. Pojedina polja se boje određenom bojom kada se menja vrednost nekog parametra. Npr. ako je asimetrija po fazama veća od neke unapred zadate vrednosti polje se boji žuto. Kada npr. nestane jedan napon ili pregori osigurač, polje se boji crveno i daje se opis uzroka kvara. Kod promene nominalnih parametara motora (npr. kada se desi preopterećenje do $5 \%$ simbol kojim je predstavljen motor boji se žuto, a ako preopterećenje postane veće onda se ovaj simbol boji crveno). Data je mogućnost da se desnim klikom na bilo koji od motora otvara meni kojim se nude brojne opcije, kao što su: broj uključenja/isključenja (u toku tekućeg dana, meseca, odnosno godine), pregled uključenja/isključenja (pregled po danima i mesecima), broj sati rada (za izabrani interval), utrošena električna energija (aktivna i reaktivna), prate se i beleže i informacije o remontima.

Podaci sa senzora temperature, pritiska, nivoa, protoka i dr. pakuju se u fajlove koji se kasnije otvaraju i pregledavaju pomoću odgovarajućeg programa. Centralna SCADA (u kontrolnoj sobi) ne "prevlači” kompletne fajlove već periodično prima i osvežava parametre sa objekata (npr. regularno na 10 min., a osim toga i svaki put kada se podigne prozor za posmatrani objekat, na zahtev operatera, ili kada se desi neka od značajnijih promena kao što su uključenja i isključenja motora, nestanci napona $i$ struja u pojedinim fazama i sl.).

Od hidrauličkih parametara prikazuju se: nivoi u rezervoarima (RR). Zavisno od toga koje su sonde potopljene prikazuje se trenutni nivo fluida u rezervoaru. RR se prikazuje pravougaonikom čije su stranice srazmerne prečniku i dubini rezervoara i prema poziciji senzora određuje se visina. Potopljeni senzorise boje zeleno, dok senzor koji je između poslednjeg potopljenog i narednog boji se narandžasto uz blinkanje. Granični (sigurnosni) nivoi, koji su praktično alarmni, boje se crveno. Po ovome je operateru jasno šta se događa u određenom RR, a ovaj prikaz se otvara kada operater pozicionira RR. S druge strane, veoma je bitan i prikaz punjenja, odnosno pražnjenja RR. Kada se mišem pozicionira neki od RR, desni klik nudi opcije kao što su: dijagram promene nivoa fluida $u$ RR, dnevni maksimumi i minimumi, dostizanje graničnih vrednosti, neregularna stanja (npr: preliv, pražnjenje RR ispod donjeg graničnog nivoa, nepostojanje informacija o stanju u RR u dužem vremenskom intervalu, pri čemu se se korisniku daju i informacije o najverovatnijem uzroku pojave neregularnog stanja). Dijagram promene nivoa na apscisi (vremenskoj osi) je klasičan dnevni, odnosno mesečni prikaz, a na ordinati je prikazan nivo fluida u RR. Pri tome se prikazuju tačke koje odgovaraju vremenskim trenucima kada je dostignut neki nivo (ove tačke nisu precizno pozicionirane na vremenskoj osi zbog određenog intervala očitavanja koji može biti npr. na $5 \mathrm{~min}, 10 \mathrm{~min}$. i sl., što zavisi od očekivane dinamike konkretnog RR).

Prikaz termičkih parametara grafički i/ili tabelarno daje sliku o temperaturi metanola, plašta rezervoara i spoljnoj temperaturi.

Hronološki registrator događaja (HRD) beleži sve promene digitalnih i analognih ulaza i izlaza i sve karakteristične događaje (isključenja pumpi od strane sistema zaštite, isključenja motora od strane operatera itd.).Pri pojavi ovakvih događaja sistem sam pokreće komunikaciju i javlja promene komandnom centru u kontrolonoj sobi. U vezi s HRD - om treba razlikovati onaj koji beleži centralna SCADA i koji sadrži informacije o svim događajima koji su se desili na raznim objektima. Da bi ove informacije imale smisla omogućena je sinhronizacija u vremenu i relativno lak pregled događaja iz HRD-a. Prva selekcija je prema objektu iz kojeg informacije stižu, tako da kada korisnik zatraži HRD za određeni objekat ne gleda čitavu listu, već samo podatke vezane za njega. Nekada je bitno videti i šta se događalo u susednim objektima da bi se otkrio uzrok, pa je data mogućnost korisniku da selektuje objekte za koje želi zajedničku listu događaja [4].

\section{Zaključak}

Prikazano je tehničko rešenje upravljačko - nadzornog sistema skladištenja i pretakanja metanola, jedne tehnološke celine kompleksnog pogona za proizvodnju biodizela. Upravljačka jedinica je PLC. Lokalni pregled i zadavanje parametara vrši se na touch panelu. Korišćen je standardni PC kao lokalni SCADA računar sa operativnim Windows sistemom i instaliranim SCADA programom. Ovaj SCADA računar, na kome se vrši arhiviranje relevantnih podataka, je ethernet komunikacijom povezan s centralnim sistemom nadzora i upravljanja u komandnoj sobi pogona za proizvodnju biodizela. Grafički interfejs kao posrednik između operatera i pretakališta metanola omogućava neprkidni nadzor procesa skladištenja i pretakanja metanola potrebnog za pripremu katalizatora koji pospešuje proces transesterifikacije biljnog ulja. Prekoračenje graničnih vrednosti određenih veličina izaziva pojavu svetlosnog i zvučnog alarma kao i ispisivanje poruke na touch panelu i SCADA računaru. Operater 
ima mogućnost kvitiranja zvučnog alarma dok svetlosni signal i ispisana poruka ostaju do otklanjanja uzroka. Omogućeno je arhiviranje podataka i generisanje izveštaja.

\section{Literatura}

[1] Gerpen, J. V., Biodiesel processing and production, University of Idaho, Moscow, Fuel Processing Technology pp 1097 - 1107, 2005.

[2] Jurac, Z., Optimiranje proizvodnje biodizela iz otpadnih jestivih ulja s obzirom na zahteve kvalitete, doktorska disertacija, Sveučilište u Rijeci, Tehnički fakultet, Rijeka, 2011.

[3] Körbitz, W., New Trends in Developing Biodiesel World - Wide, Evaluating \& Exploating the Comercial Uses of Ethanol, Fuel Alcohol \& Biodiesel, Singapore 2002.

[4] Stankov, S., Glavni elektro projekat energetike i automatike Pogona za proizvodnju metil estra biljnih ulja u fabrici FAM ad Kruševac, 2008.

[5] Stankov, S., Z. Stajić, S. Perić, Centralni sistem za nadzor i upravljanje u JKP "NAISSUS, Niš, 31. Stručno - naučni skup s međunarodnim učešćem, Vodovod i kanalizacija 2010, Zbornik radova, Divčibare, str. 129 - 138, 2010.

[6] http://www.miel.si/wp-content/VsebinaPDF/V083-E1-21+NS-Series+SetupManual.pdf 